\title{
CARTOGRAFÍAS CONTEXTUALES
}

\author{
Falco (Fernando Falconí)
}

\section{Resumen:}

Desde múltiples fuentes, estudios y prácticas, propongo un concepto, dinámica de producción/ ejecución y laboratorio denominado "Cartografías Contextuales", en el cual los talleristas de manera individual visitan nuevamente lugares que hayan sido importantes en sus vidas, para resignificar esas experiencias y darles formas otras a través del lo creativo, estético y poético. Esta primera posibilidad busca ser una instancia que aporte también en el beneficio psico-emocional de los participantes. Una segunda opción dentro de la propuesta general plantea relacionar lugares específicos de la ciudad con temas y problemáticas de carácter más social, en un sentido crítico y propositivo, para así mismo desarrollar productos de visibilidad pública con la intención de aportar en la concientización y solución de dichas problemáticas dentro del contexto de esa ciudad e incluso en una dimensión mas ampliada.

Palabras claves: Contexto, Ciudad, Psicogeografía, Autoconocimiento, Transformación, Arteterapia, Social, Crítica, Acción, Cartografía

\begin{abstract}
:
After reading multiple sources, studies and practices, I propose a production/realization dynamic, and a laboratory called "Cartografías Contextuales." In this experience, contributors revisit alone places that have been important in their lives, to re-signify their events and reshape them through creativity and poetics. This exercise seeks to contribute to the partakers psico-emotional viewpoint. This proposal considers, in a critical and proactive sense, the relation between specific places in the city and social issues, in order to develop artistic products that are evident to public awareness in order to develop answers to these issues in the city, and even, in an extended aspect.
\end{abstract}

Keywords: Context, city, psico-geography, self-awareness, transformation, art therapy, social, critique, action, cartography

\footnotetext{
Autor:

Falco (Fernando Falconí), Cuenca. Artista transdisciplinar. Máster en Arte y Nuevas Tecnologías en la Universidad Europea de Madrid, Espańa. Licenciado en Artes Visuales en la Universidad de Cuenca, Ecuador. Tiene reconocimientos y selecciones nacionales e internacionales en arte contemporáneo (artes visuales, arte de acción, arte público, inserción de arte en la esfera pública, arte contextual, arte y comunidad, arte relacional).
} 


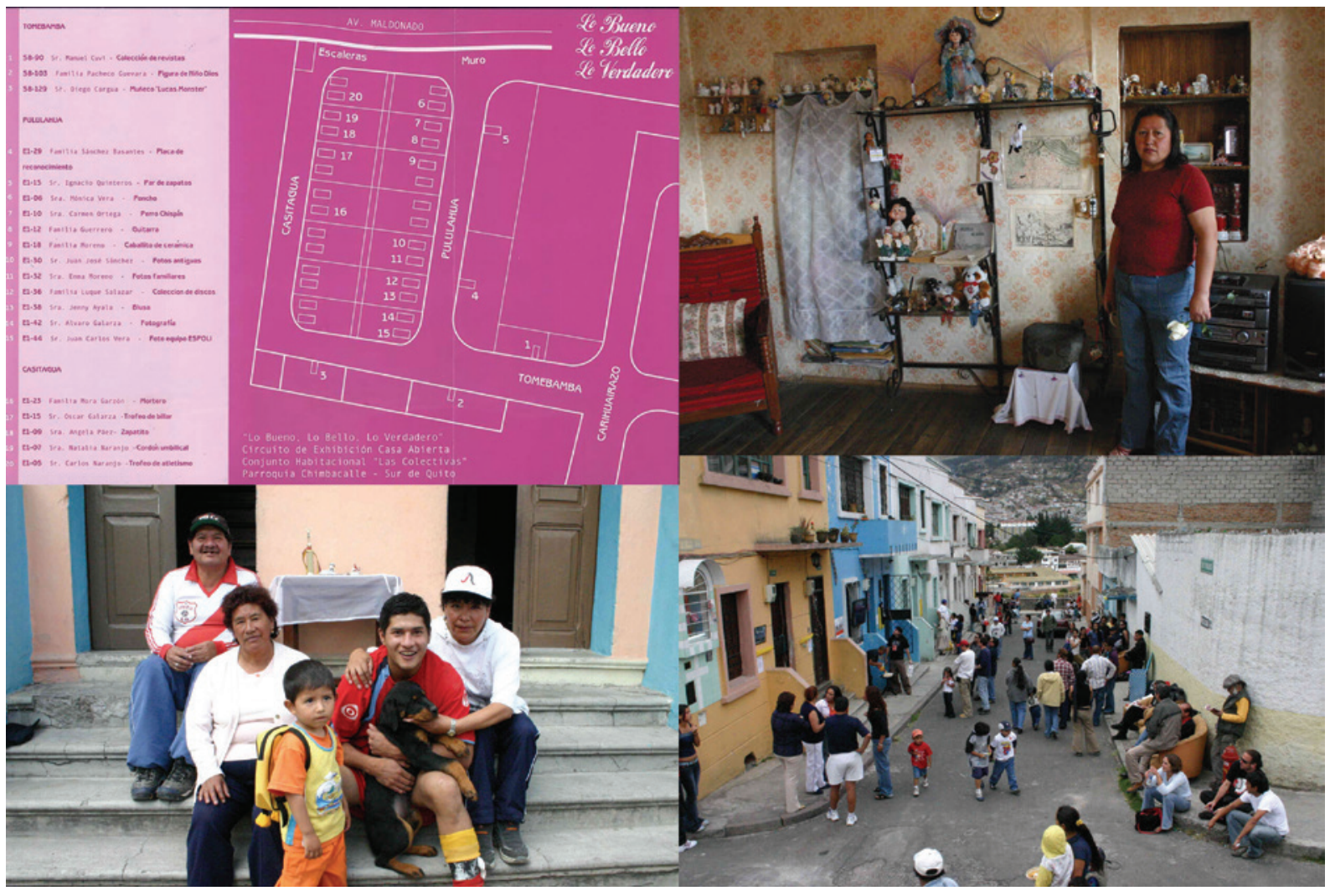

1. “Lo Bueno, lo Bello, Lo Verdadero”, Fotos: Tranvía Cero, Falco, 2005.

Desde el año 2009, en mis clases de la Carrera de Artes Contemporáneas de la Universidad San Francisco de Quito, estudiamos y practicamos diferentes ejercicios relacionados con derivas urbanas, la Teoría de la Deriva ${ }^{1}$ y la Psicogeografía ${ }^{2}$. En estas líneas, se han hecho recorridos urbanos en los que les solicito a los chicos que se abandonen a las condiciones físicas/sensoriales del paisaje, del entorno,

1 Deriva: "Modo de comportamiento experimental ligado a las condiciones de la sociedad urbana: técnica del pasaje apresurado a través de ambientes variados. Se usa también, más particularmente, para designar la duración de un ejercicio continuo de esta experiencia." V.V.AA., 1977:25

2 Según Debord: "La psicogeografía se propone el estudio de las leyes exactas, y de los efectos precisos del medio geográfico, planificados conscientemente o no, que afectan directamente al comportamiento afectivo de los individuos". prestando especial atención a los estímulos o efectos psíquicos y emocionales que el mismo les provoque. Cada uno escogía el punto $A$ desde donde empezarían su deriva, pero no tendrían un punto $B$ definido al cual arribar. Sabrían cual sería su punto $B$ al llegar a él, después de mínimo una hora de caminata. En estos ejercicios individuales, en los que les solicitaba que vayan solos y a pie, también les pedía que lleven herramientas para hacer registros varios: cámara de fotos/video, celulares, una libreta de apuntes, etc. Después que realizaban sus incursiones citadinas, en sesiones grupales revisábamos los resultados y registros multimedia. A partir de este recorrido y del material generado en el mismo, así como de las ideas, reflexiones y sensaciones producidas tras estos tránsitos, proponían una obra a trabajar con los materiales y técnicas 
que quisieran. Debo anotar que este ejercicio lo hacíamos después de abordar temas como arte en espacios públicos, inserción de arte en la esfera pública, arte contextual y arte relacional.

Además, en una clase anterior, habíamos estudiado/practicado también ejercicios relacionados con el arte de acción, abordando temas como el "happening", "performance" y acto poético. Estudiamos el acto poético desde la noción de Alejandro Jodorowsky, quien en su libro "Psicomagia" habla de él en todo un capítulo, previo a otro dedicado a los actos psicomágicos en esa misma publicación.

\section{Psicomagia en varios actos}

La Psicomagia, propuesta de Jodorowsky, es una técnica que combina elementos de la tradición del psicoanálisis y psicoterapia, así como de prácticas de sanación o de búsqueda de bienestar menos ortodoxas, como el shamanismo, la curación energética e incluso prácticas mítico-mágicas de brujos y curanderos, más técnicas del teatro y del "efímero pánico". Parte de lo que propone el ya legendario autor chileno-francés es que la fuerza de nuestro inconsciente actúa de tal manera sobre nuestro consciente que puede o podría sanar y equilibrar desórdenes tanto de nuestra mente como de nuestro cuerpo y espíritu. Para ello recurre a diferentes "prescripciones", tareas o recetas a cumplir por quienes solicitan ayuda: acciones que trastocan la lógica cartesiana o de las ciencias médicas. Ahí reside también el poder de lo simbólico y subjetivo sobre la objetividad y el estructurado orden cotidiano, llegando a provocar y remover niveles más profundos de la conciencia y la psiquis de los individuos.

Operando desde ahí, la psicomagia conseguiría incluso aliviar o sanar enfermedades y trastornos que la medicina, psicología y psiquiatría tradicionales no consiguen ${ }^{3}$, todo esto desde aplicaciones creativas y actos estético-poéticos, transgresores o surrealistas muchos de ellos, que nos remiten también al "happening", "performance", intervenciones e instalaciones en el arte. Según Jodorowsky, "la psicomagia no pretende ser una ciencia, sino una forma de arte que posee virtudes terapéuticas".

\section{Mapeando lo objetivo/subjetivo, lo individual/colectivo}

Como ejemplificación de casos en los que he trabajado (desde prácticas artísticas y sociales), relacionados con contextos específicos, comunidades y la aplicación de mapas o cartografías, anotaré:

En el 2005 dentro de "Lo Bueno, Lo Bello, Lo Verdadero", proyecto desarrollado en el III Encuentro Internacional de arte urbano al zur$i c h^{4}$, desde el concepto que planteé más el trabajo comunitario, se exhibieron conjuntamente en el mismo barrio "Las Colectivas" (parroquia de Chimbacalle, sur de Quito) un objeto, pieza o elemento que una familia o un vecino de ese barrio consideraba que era el más bueno, bello o verdadero que tenía. Fueron veinte los objetos expuestos en el interior de sendos hogares que se abrieron para que pudieran apreciar esas piezas, además de conocer más sobre su historia y contexto. Para facilitar la visita a estas casas, se imprimió una guía de mano en la cual constaba un mapa de este circuito de exhibición Casa Abierta.

Dentro de este mismo Encuentro, en su séptima edición en el 2009 desarrollamos junto con un grupo de diez personas no videntes el proyecto "Cartografía Cuarta", en donde mapeábamos lo

3 La Psicomagia no es una técnica científica. El mismo Jodorowsky reconoce que no se sitúa "en el terreno científico".

$4 \mathrm{Al}$ zur-ich: Encuentro de Arte y Comunidad (s.f.).

Consultado en marzo 20, 2015, de

http://arteurbanosur.blogspot.com 


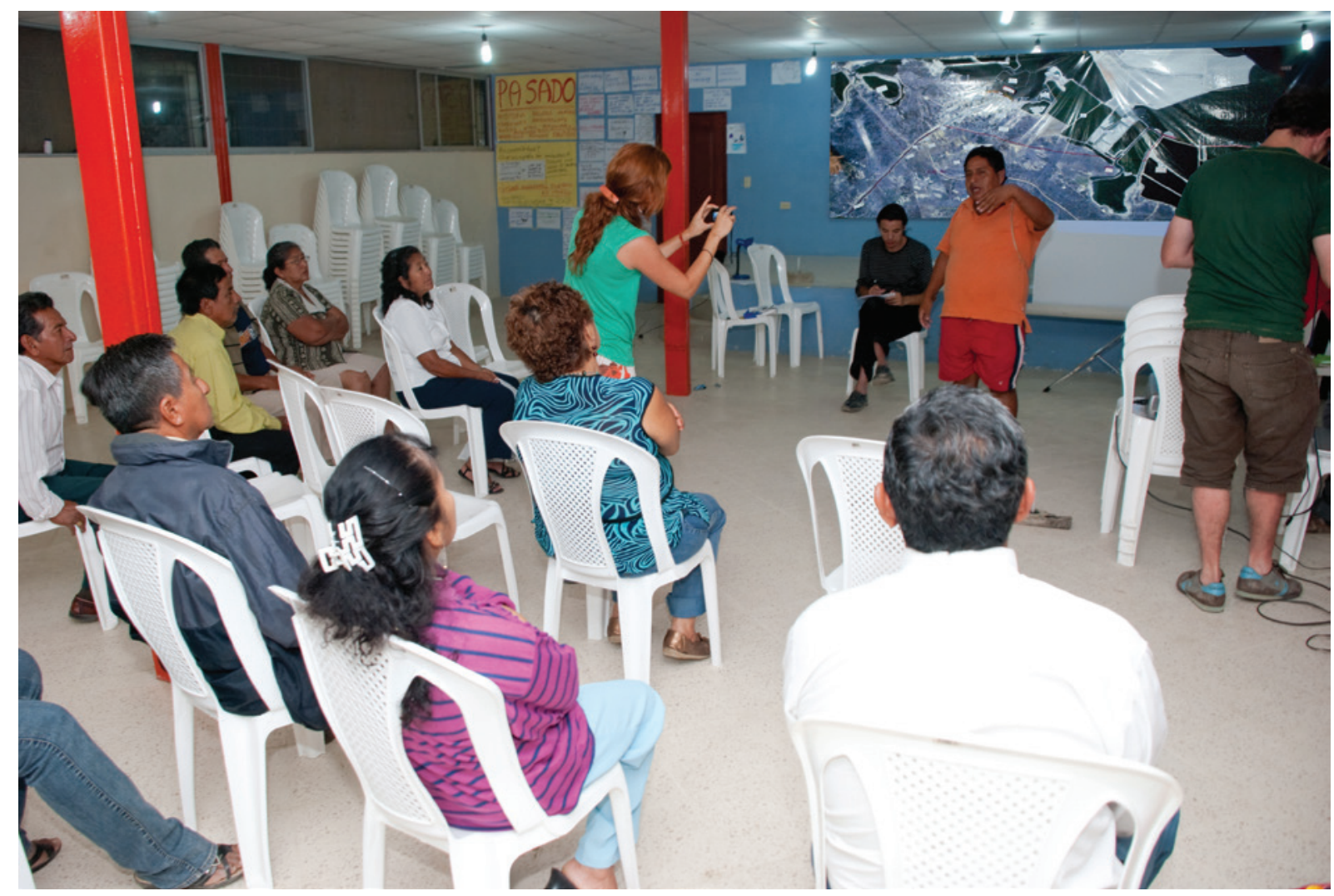

2. “Mapa Vivo”, Foto: Javier Lazo, 2009.

que cada uno de ellos consideraba el lugar más bello de la ciudad, atendiendo obviamente no al sentido de la vista sino a los otros cuatro. Los acompañaba del brazo a ese lugar específico, hacía un registro fotográfico del mismo pero sobre todo hacía un registro en audio del testimonio individual de por qué este lugar, de todo Quito, era el más hermoso para cada uno de ellos. Dichos audios fueron integrados a un mapa interactivo en línea, pueden ser escuchados desde la demarcación de esos lugares físicos en esa representación multimedia de la ciudad.

En ese mismo año, en el marco del programa de arte y comunidad "Solo con Natura", realicé un proyecto dentro de la residencia en Puerto el Morro, provincia del Guayas. La propuesta

5 Franja Arte-Comunidad (s.f.). Consultado en marzo 20, 2015, de

http://www.soloconnaturaecuador.org fue desarrollar en colaboración y coautoría con la comunidad un "Mapa Vivo". Como soporte gráfico y metodológico para el mismo utilizamos la gigantografía de una vista satelital del Puerto. Durante una semana fuimos marcando en dicho mapa -ubicado en la pared principal de la Casa Comunal- hitos históricos y actuales en la vida del Puerto, atendiendo a parámetros humanos, sociales, culturales, políticos, ecológicos, etc. Este soporte gráfico se convirtió en un pretexto para plenarias, reflexiones y dicusiones comunales sobre territorialidad, identidad, integración, memoria, patrimonio, desarrollo, bienestar, entre otros. Todo este proceso y construcción del "Mapa Vivo", articulado de manera contextual y democrática, lo desarrollamos desde la participación y testimonios colectivos y comunitarios. Este mapa intervenido y ampliado en su demarcación permanence 


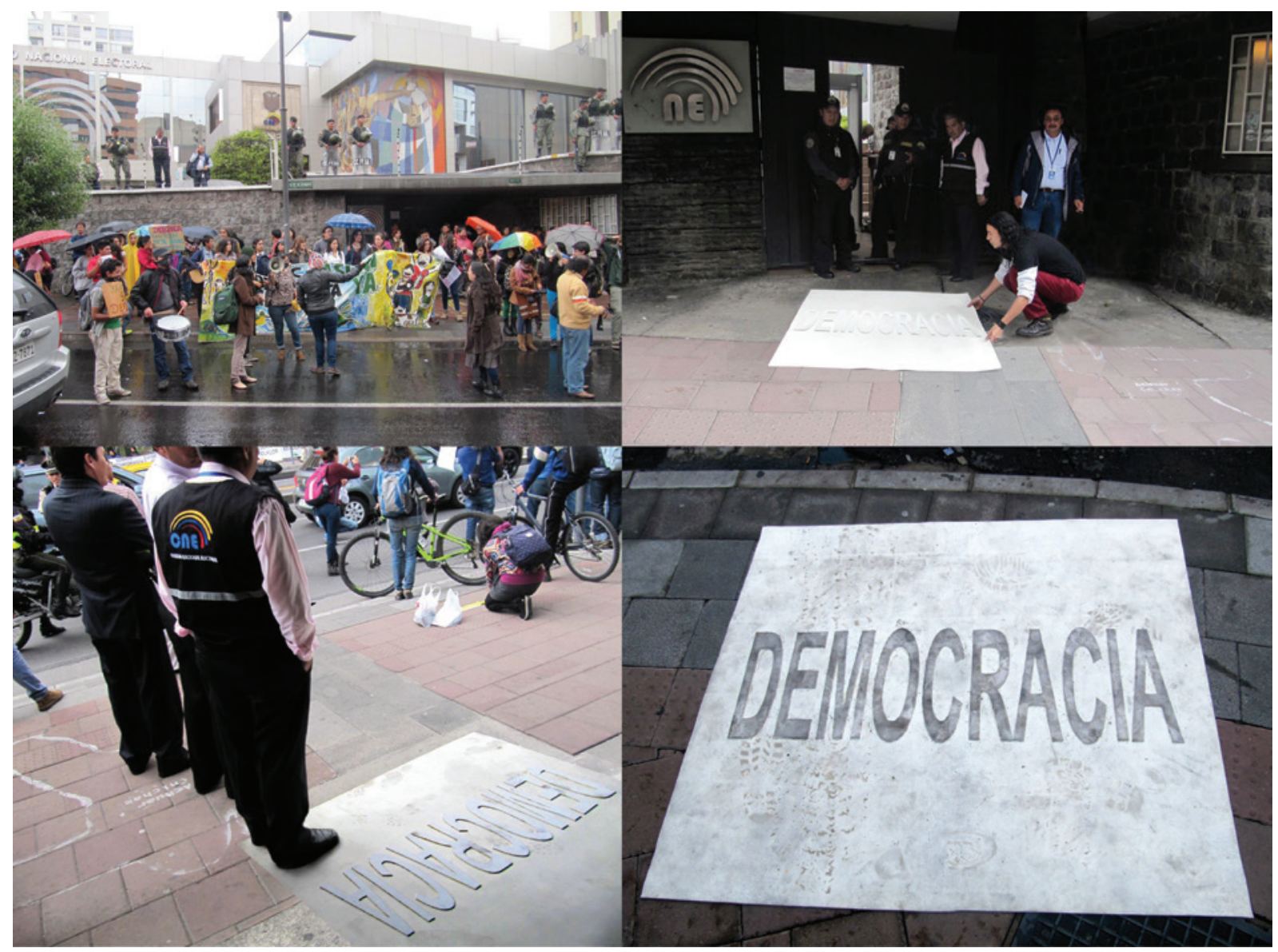

3. "Democracia”, CNE-Quito. Evento: Acciones Artísticas por el Yasuní y la Democracia. Fotos: Carlos Vargas, Falco, 2014.

aún en la casa comunal, es una herramienta al servicio de la comunidad de Puerto el Morro.

\section{La propuesta en curso}

En el arteterapia, ${ }^{6}$ las prácticas creativas y comunicacionales a través de medios y herramientas artísticas son también mecanismos decatarsis, desahogo y alivio para el bienestardelas

6 Según la Asociación Americana de Arte Terapia (AATA, 2013), consolidada en 1969: "El arteterapia es una profesión establecida en la salud mental que ocupa los procesos creativos de la realización de arte para mejorar y explorar el bienestar físico, mental y emocional de individuos de todas las edades. Está basado en las creencias que el proceso creativo relacionado en la autoexpresión artística ayuda a la gente a resolver conflictos y problemas, desarrollar habilidades sociales, controlar el comportamiento, reducir el estrés, aumentar el autoestima y la autoconciencia, y alcanzar la introspección." personas, tanto a nivel individual como colectivo. Ciertas nociones y aplicaciones del arteterapia, conjugadas con: mis estudios y prácticas artísticas, los proyectos contextuales y comunitarios en los que he trabajado, el desarrollo de mapeos y sistemas cartográficos como visualización y organización de contenidos y datos, mi experiencia como docente y la aplicación en mis clases de temas como la psicogeografía y la deriva urbana, más los actos poéticos y la psicomagia desarrollada por Jodorowsky, me llevaron a generar y ensayar una propuesta a la que llamé "Cartografías Contextuales". Este concepto, dinámica de producción/ejecución y laboratorio se ha ido desarrollando y afinando con el tiempo, pero consta básicamente de dos parámetros y aplicaciones que lo sustentan: 


\section{Ala 1}

Desde el ańo 2010 trabajo con estudiantes universitarios de arte un ejercicio al que llamé "revisitas contextuales", en el cual solicito que cada uno, de manera personal e individual, regrese a un lugar específico de la ciudad que para ellos sea significativo en sus vidas, por hechos que ahí les haya ocurrido: algo único, especial o trascendental, ya sea por lo bueno o malo que ese acontecimiento pueda ser y representar tanto a nivel vivencial como a nivel energético y simbólico en sus existencias, en sus registros emocionales/corporales, en sus cronologías e imaginarios propios.

A base de esta revisita, a la experiencia de volver a registros de este proceso, se generan propuestas que artística y poéticamente recontextualizan y dan cuerpos otros a dichos sucesos, a sus significados y significantes, a las memorias y huellas de los mismos. Cartografiamos así una ciudad como un territorio y un archivo psicogeográfico, marcando estas instancias tanto espacio-temporales como psicoemocionales, resignificándolas mediante propuestas visuales, objetuales, audiovisuales, performáticas, relacionales, de intervención en espacios públicos y privados, site specific, etc.

\section{Ala 2}

La segunda ala surge así mismo de mi quehacer artístico, más activismos sociopolíticos y vinculaciones con diferentes movimientos y luchas sociales, esto en relación con ya conocidas prácticas no solo artísticas sino de protesta, activismo civil y creatividad ciudadana en general. Esta otra posibilidad va también dirigida a metodologías de mapeo e intervención de una ciudad. Consiste en ubicar determinadas instancias, focos o estatutos de problemáticas y tensiones específicas en cuanto a agendas humanas, sociales, políticas y culturales, relacionándolas con el espacio físico, arquitectónico, urbanístico, y las representaciones tanto formales como conceptuales, ideológicas y simbólicas en y para una ciudad. Esto lleva o puede llevar a realizar intervenciones, instalaciones, acciones, situaciones, manifestaciones, relaciones $\mathrm{y}$ experimentos sociales site specific en zonas, edificaciones, inmuebles, construcciones e instituciones relacionadas con temáticas como: violación de los derechos humanos-derechos de la naturaleza-derechos ciudadanos-derechos culturales, casos puntuales de corrupción, abusos de poder, discriminación, etc., es decir, sensibilización social y movilizaciones personales o grupales sobre problemáticas y agendas específicas.

Así mismo se investigan, detectan y mapean dichos lugares, para proceder a realizar ahí propuestas individuales, colectivas y sociales contextuales al espacio físico-simbólico: tomas de posición de carácter reflexivo, crítico y contestatario, apelando a creatividades, estéticas y poéticas múltiples.

Los resultados conseguidos en ambas alas, las propuestas elaboradas por cada tallerista son exhibidas al cierre del laboratorio en un espacio de acceso público, ya sea como una obra resuelta o como un trabajo en proceso. Además, como parte de la metodología de Cartografías Contextuales, de la sistematización de contenidos y exhibición de los resultados, se ubican en un mapa también expuesto los puntos de la ciudad donde cada participante volvió en su revisita contextual, o que marcó como el lugar en la urbe relacionado con la problemática de carácter social abordada. 


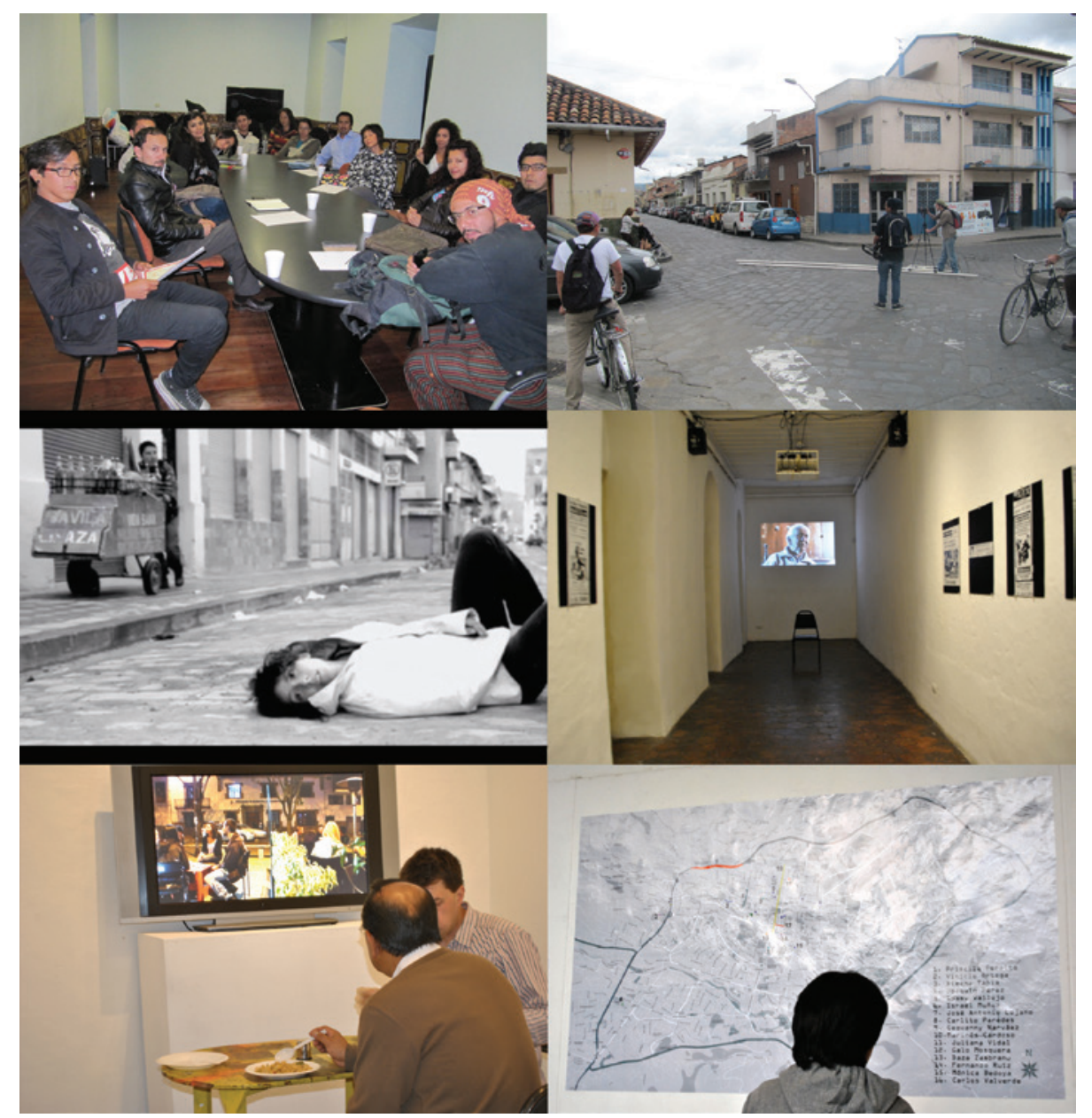

4. "Cartografías Contextuales Cuenca”, Fotos: Mateo García, Kym Cochran, Falco, 2015.

\section{Estado actual}

A partir de enero del 2015, la propuesta Cartografias Contextuales invita a creadores $\mathrm{y}$ artistas de todas las disciplinas a participar en cualquiera de las dos modalidades antes planteadas, se extiende a otras ciudades más allá de Quito y amplia además la posibilidad que no solo sean personas vinculadas directamente con lo artístico y creativo quienes integren el taller/laboratorio/exposición, sino que sea la ciudadanía en general quien pueda participar de estas convocatorias, dinámicas y prácticas en el campo expandido. Parte del concepto fundamental de Cartografías Contextuales es poder abrir su espacio de reflexión, del compartir y del producir más allá del campo artístico y sus circuitos tradicionales. Considero que al hacer estas revisitas contextuales hay una instancia de beneficio personal e individual (sobre todo en el Ala 1), principalmente a nivel vivencial, simbólico y psíquico más allá de la resolución artística, técnica y estética que los productos comunicacionales puedan tener, en términos de la búsqueda y los resultados de una forma de transformación energética y de la memoria tanto corporal como emotiva a través de ejercicios y aplicaciones formales. Este es un aspecto de gran interés para mí, y que trasciende el propósito o intención de conseguir al final "obras artísticas" a declarar, legitimar y exhibir en los espacios y circuitos del arte. De todas maneras, hay una búsqueda, 
experimentación y exploración dirigidas a los resultados técnicos y estéticos a conseguir, pero esto más allá de "lo oficial artístico", desde un lugar abierto, receptivo y catalizador de los diferentes, diversos e ilimitados modos creativos y expresivos de todas las personas, así como en las diferentes destrezas técnicas de cada participante. Esto se enfoca principalmente en las posibilidades de concebir, desarrollar y producir imágenes, formas, sonidos, acciones, etc; otros, más allá de lo convencional, de lo predecible, de lo ya estructurado, de lo ya conocido/vivido/asumido... terminen o no los resultados al ser llamados "arte", pues ya estamos trabajando con diversos estados y capas psíquicas (preconsciente, consciente, inconsciente $y$ subconsciente) cuando recurrimos a imaginarios e imaginados, a instancias de la memoria, el olvido, las reminiscencias y los rastros, así como también a la configuración/desconfiguración no solo de mundos reales o vividos, sino también de mundos posibles, de universos otros. Apelamos también a todo el potencial y la fuerza de lo simbólico, metafórico y poético como una forma de trastocar, de trascender configuraciones cotidianas en nuestras vidas, ya sea desde estructuras y constructos históricos, así como desde sentires, quereres, accionares y producciones del día a día.

En primer término, concibo, propongo y ensayo a las prácticas creativas, estéticas y artísticas como una metodología de autoexploración y autoconocimiento, y también como una aplicación y sistémica en la búsqueda $\mathrm{y}$ desarrollo de autorrealización tanto individual como colectiva. Y luego, me interesa que esta vía, este camino trascienda a su vez los términos, condiciones, protocolos y limitaciones del sistema artístico convencional, que también es un sistema de inclusión/exclusión, de configuración de categorías y estatus diferenciales entre los artistas y los "no artistas", un sistema de articulación y ejercicio de poder en lo que la institución arte y lo instituido artístico condicionan y limitan las posibilidades y potencialidades de quienes se encuentran fuera de sus lógicas de campo y de sus mecanismos de producción, distribución y consumo, así como de la capitalización y especulación de "lo artístico" desde su valor de uso y de cambio.

En este sentido, me interesa más el capital humano, su desarrollo personal y las posibilidades de apoyo terapéutico y de sublimación del tema o problema desde ejercicios y prácticas vinculadas con lo artístico, así como también la sensibilización y concientización -ya en la esfera pública- sobre problemáticas sociales varias, a través de metodologías y resoluciones creativas y estéticas, todo esto desde la permanente necesidad y el desafío de mejorar tanto nuestra calidad de vida y salud psicoemocional y afectiva, como nuestros procesos relacionales y de convivencia con el resto. En esta dimensión ampliada, me interesa también el reflexionar, debatir y aportar en agendas más extensas que involucrarían temas como los derechos humanos, las equidades/inequidades y las luchas sociales; es decir, la búsqueda de un beneficio, equilibrio y trascendencia no solo individual sino también colectivo, más allá que seamos o no artistas. Búsquedas, definiciones y cambios positivos y propositivos desde el ser humanos, ser ciudadanos, ser diversos; desde nuestras realidades, intenciones, posibilidades y potenciales propios, que a la vez toman sentidos y trascendencias otras en el campo, los campos expandidos y compartidos en la sociedad.

\section{Bibliografía}

Dalley, T. \& C., (1992). C. The Handbook of Art Therapy. London, UK:Tavistock/Routledge.

Debord, G., (1955). Introduction à une critique de la géographie urbaine. Journal Les Lèvres Nues \#6, Bélgica. 
Debord, G., (1958). Teoría de la Deriva. Revista Internationale Situationniste \#2, París, Francia: 32, Rue de la Montagne-Geneviève.

Debord, G., (1977). "Teoría de la deriva" en La Creación abierta y sus enemigos, textos situacionistas sobre arte y urbanismo, introducción y traducción de Julio González del Río Rams. Madrid, España. Ediciones La Piqueta.

Indij, G., (2001). Grupos, movimientos, tendencias del arte contemporáneo desde 1945. Buenos Aires, Argentina, La Marca Editora.

Jodorowsky, A., (2005). Psicomagia. Madrid, España: Ediciones Siruela, S.A.

Web de Cartografías Contextuales: http://falcofer.wix.com/cartogcontex 